\title{
BIOGAS TECHNOLOGY
}

\author{
A.N.S. KULASINGHE \\ National Engineering Research \& Development Centre, Ekala, Ja-ela.
}

I have chosen to present to you some aspects of biogas on which a certain amount of work has been done in this country. Biogas is familiar to everybody but it is normally associated with cow-dung and other faecal matter. There are problems regarding the use of cow-dung for biogas because cow-dung has to be fed practically every day. It is dissolved in water and the percentage of solids within the biogas digester is very very small and can be less than $10 \%$ of the weight of the water. So, you have a large digester with a small amount of material. Another aspect is that apart from the gas itself, it produces a very good fertiliser and today natural fertiliser is extremely valuable. But the problem is that the fertiliser you get in the effluent from this digestion is mainly water. So that if you have to transport it to a distance, it is extremely inconvenient. It can be used mainly within the same premises. There are also other problems. You have to watch $\mathrm{pH}$ value of the material inside the digester and the formation of scum. Scum formation is a serious problem because when it occurs the gas generation process is stopped, as the scum prevents gas coming out and some sort of arrangements should be made to use a stirrer to break up the scum. As I mentioned earlier, the material for the digester has to be fed everyday and when a certain amount is fed an equal amount comes out which has been digested. The retention time may be up to a month.

At the NERD Centre, we started work years ago, on trying to improve this situation. We tried various types of digesters to overcome some of the problems of gas tightness and similar problems associated with digesters. In the process of solving these problems, we evolved certain solutions. Instead of charging the digester every day, charging was done at longer intervals. To avoid the scum formation, we increased the amount of solid matter within the digester with very little water added. This gave rise to a batch type of digester. The material used to feed the digester is straw, various weeds and similar material. The digestion takes place over a very long period. In fact, our laboratory experiments showed that we could digest it over a period of over one year with gas being generated all the time. We finally adopted a six months cycle especially with straw. The reason for that is that the cropping cycle is about 6 months in this country. It is possible to get the straw from one crop, digest it for six months and take out the digested material for the next charge for use as the fertiliser for the next crop. This has been tried out for a long time with complete success. We have found that it is possible to digest, say 80 to $100 \%$ of the straw out of a paddy field to give adequate fertiliser for that paddy field without any other fertiliser. It is therefore not necessary to use any of the conventional chemical fertilisers for paddy cultivation. You take the straw from one crop, put it into the digester, get gas during a period of 6 months, after which it is ready as fertiliser for the next crop. It is something which does not require messy handling of digestible material every day. Apart from the straw, we use a small amount of cow-dung to initially provide the bacteria for the 
anaerobic digestion. It can be improved also by increacing the nitrogen, carbon ratio with an addition of a very small amount of urea, say one to two percent which is insignificant. That is not very necessary. The cow-dung to provide the bacteria is necessary during the first 6 months. After that the bacteria will remain in the digester, if the water is not taken out.

Apart from the digestion of straw which can make the farmer independent of chemical fertiliser for his paddy field, he gets gas for his cooking and lighting. Other material also can be digested in this manner quite successfully and recently we have been working on the digestion of garbage. Market garbage which amounts to about 100 tonnes a day in Colombo, can be digested. But the period of digestion is shorter; it becomes nearly 4 months. We have prepared a project with one hundred and twenty 100 tonne digesters for the Colombo Municipality.

The Colombo Municipality has to deal with 10 tonnes of offal a day which was creating serious problems for them. There was a proposal being considered by the Colombo Municipality for the import of an incinerator for burning of 10 tonnes of offal a day. It was estimated to cost Rs. 52 million. It was also designed for making use of liquid fuel for burning the offal. At this stage, I was contacted by a Municipal Councillor who asked me whether there was no better way of doing this. I put up a proposal to the Mayor of Colombo and the Finance Committee of the Municipality to deal with 10 tonnes of offal plus 100 tonnes of market garbage a day using a process developed at the NERD Centre. Market garbage is easily digested but offal was believed to be unsuitable for anaerobic digestion. However, experiments carried out at the NERD Centre indicated that offal could be digested, although the Australian supplier of the incinerator, said that this could not be done. However, offal was digested at the NERD Centre. Further investigations revealed that the best solution is to use anaerobic digestion for the market garbage and use a small portion of biogas produced to process the offal to produce animal feed. This proposal estimated to cost Rs. 24 million provided for one hundred and twenty 100 tonne digesters for market garbage which will produce 100 tonnes of fertiliser plus about $5000 \mathrm{~m}^{3}$ of biogas per day. Using part of the biogas as fuel, it is possible to produce $21 / 2$ tonnes of animal feed a day, making a production value of about Rs 50,000 worth of fertiliser and about Rs 10,000 worth of animal feed. All this is possible with the investment of a sum of only Rs 24 Million which is less than half the cost of the incinerator to burn 10 tonnes of offal a day.

This is an aspect of biogas which is not known generally, but serves as a solution to garbage disposal in towns.

The NERD system provides for the digestion of paddy straw for the production of fertiliser and biogas. With the anaerobic digestion of about $80 \%$ of the straw from a paddy field, it is possible to meet the full fertiliser requirements of the paddy field plus sufficient biogas for the cooking and lighting requirements of the farmer. An acre of . paddy produces about a tonne of straw. Digesting this straw will supply the fertiliser and energy requirements of the average farm. No other fertiliser is normally required 
except that in phosphate deficient soils some additional phosphate has to be added. The digested material supplies the usual N.P.K. along with a number of micro nutrients required for plant growth. The use of this fertiliser brings back the fertility of the soil which has been affected by the use of chemical fertiliser and also restores the ecology which existed prior to the use of chemical fertiliser. The cost of a digester for 1 tonne of straw is about Rs 7,000/-.

The period of digestion is adjusted to be 6 months, so that straw from one crop can be used as fertiliser for the next crop in double cropping which is the normal practice in paddy cultivation in this country.

This system which is called the NERD Dry-Batch system was developed at the NERD Centre to solve a number of problems associated with biogas production. It is a unique system that had not been used anywhere else in the world. 